\title{
Durability of Internally Insulated Historical Solid Masonry under Future Climates: A Stochastic Approach
}

\author{
Sahar Sahyoun ${ }^{1}$, Lin Wang ${ }^{2}$, Hua Ge ${ }^{3}$, Maurice Defo ${ }^{4}$ and Michael Lacasse ${ }^{5}$ \\ ${ }^{1}$ Ph.D. Student, Concordia University, Montreal, Canada; s_sahyo@concordia.live.ca \\ ${ }^{2}$ Post-Doctoral Fellow, Concordia University, Montreal, Canada; forestwang2013@gmail.com \\ ${ }^{3}$ Associate Professor, Concordia University, Montreal, Canada; hua.ge@concordia.ca \\ ${ }^{4}$ Associate Research Officer, Construction Research Centre, National Research Council Canada, \\ Ottawa, Canada; Maurice.Defo@nrc-cnrc.gc.ca \\ ${ }^{5}$ Senior Research Officer and Team lead, Façade Systems and Products, Construction Research \\ Centre, National Research Council Canada, Ottawa, Canada; Michael.Lacasse@nrc-cnrc.gc.ca
}

\begin{abstract}
Today, it is globally known that climate change needs to be addressed to mitigate its harmful effects on our environment. It is also common knowledge that the contribution of historical buildings to the energy consumption of the existing Canadian building stock is severe. Buildings of historical identity are often poorly thermally insulated. Thus, to increase energy efficiency and occupant comfort in cold climates, the application of thermal insulation on the interior side of solid masonry walls offers a possibility to improve the historic buildings' energy performance, without compromising their identity and cultural heritage values. As a result, the historical masonry will be subjected to lower temperature during the heating season, which can increase the potential for condensation and frost within the wall. A balance must therefore be reached between durability measures and thermal performance objectives. This paper intends to achieve this balance through determining the impact of the interior insulation thickness on the durability of a typical historical masonry wall under the effect of climate change. A stochastic approach is used in hygrothermal simulations to account for the uncertainty in material properties. Results in Ottawa indicate a higher risk to frost damage after interior insulation is added to a brick wall having a moisture critical degree of saturation (Scrit) of 0.25 and 0.35 . Moreover, both deterministic and the stochastic results were in good agreement. Also, both methods showed an increase risk to frost damage under a changing climate.
\end{abstract}

Keywords: Historical Buildings, Solid Masonry, Stochastic Approach, Future Climates, Durability.

\section{Introduction}

One typical way to reduce a building's heating energy consumption is insulating its envelope. Generally, exterior insulation systems are considered the best alternative to retrofit existing buildings due to their ability to prevent thermal bridges (Straube et al., 2012). However, in the case of historical buildings, exterior insulation is not possible due to architectural and aesthetical reasons. Thus, the only way to retrofit these buildings is through adding interior insulation. Straube et al. (2012) suggested spraying an airtight insulating foam directly to the interior side of the existing masonry. However, normally after insulation is installed, the moisture content of the masonry wall increases, which may lead to a higher potential for hygrothermal problems, such as frost damage. 
Frost damage is one of the main reasons threatening durability of masonry structures in cold climates. Previous research has shown that under a changing climate, higher rainfall intensity, strong winds, and more frequent storms are expected, which may increase WDR loads on the façade and subsequently, risks for rain penetration (IPCC, 2001). On the other hand, increased solar radiation and air temperature may increase the drying potentials. It is therefore important to assess the effect of climate change on the potential risk to freeze-thaw (FT) damage.

The hygrothermal performance of masonry walls are usually assessed by means of deterministic approach. Though, the hygrothermal responses are influenced by stochastic factors, such as the variability of material properties, boundary conditions and environmental loads. The uncertainties of the input parameters may lead to a deviation between simulation results and the actual performance of the wall assemblies, consequently, leading to faulty designs.

The objective of this paper is to investigate the impact of the interior insulation thickness on the freeze-thaw damage risk of the existing masonry wall assemblies. A masonary basewall and three retrofit options having three different insulation thicknesses were tested. First, a deterministic approach was used to evaluate the hygrothermal performance of wall assemblies using Delphin. Second, a stochastic approach was used to take into account the uncertainties in brick masonry properties under different climate conditions and design configurations.

\section{Methods}

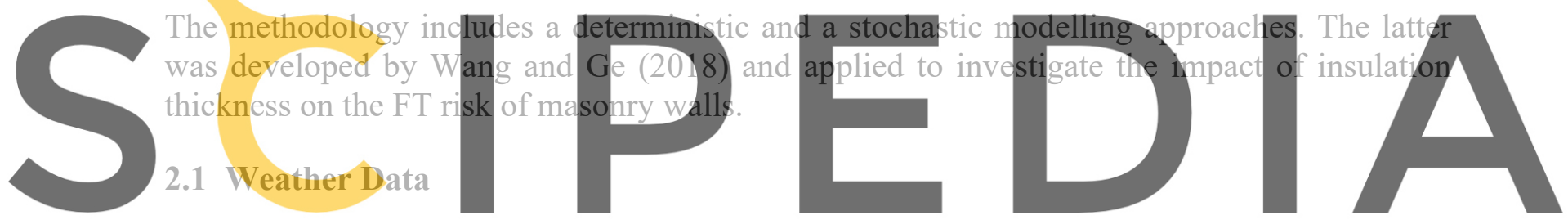

Weather data for Ottawa were provided by the National Research Council of Canada (NRC). A

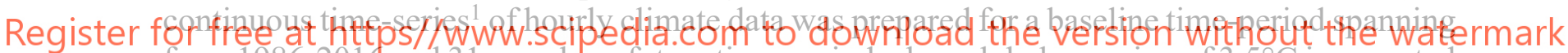
from 1986-2016 and 31-year long future time-period when global warming of $3.5^{\circ} \mathrm{C}$ is expected to be reached in the future (Gaur et al., 2019). Future data of $3.5^{\circ} \mathrm{C}$ increase, will be reached between 2062-2092 (Environment and Climate Change Canada, 2018). Each data set includes 15 realizations; however, only the median realization based on MI was used.

\subsubsection{Selection of reference years}

The selection of reference years was made with the intention to test wall assemblies under more representative design weather years in the selected timelines. Annual average of the Moisture Index (MI) (Cornick et al., 2003) and Severity Index (Isev) (ASHRAE, 2010) were computed for the chosen time-periods, and the years were ranked in ascending order. The year corresponding to the 97th percentile (ranked second out of the 31 years) in each time-period was chosen as the MRY. Table 1 summarizes the selection of MRYs under historical and future time-periods.

\footnotetext{
${ }^{1}$ The full dataset can be accessed from: 10.17605/OSF.IO/UPFXJ.
} 
Table 1. Summary of selected moisture reference year and their values.

\begin{tabular}{lccc}
\hline City & Data & MI - MRY & Isev_MRY \\
\hline \multirow{2}{*}{ Ottawa } & Historical & 2010 & 2009 \\
\cline { 2 - 4 } & Future & 2085 & 2066 \\
\hline
\end{tabular}

A comparison was then made between the selected MRYs weather data, as shown in Figure 1 for historical and future data. The temperature difference between the MI and Isev MRYs was not as significant as the difference of their rain amount. Monthly rain variation looked relatively uniform throughout the year for MRYs selected by the MI method (2010 and 2085) and considerably less than that found for the years selected using the Isev method (2009 and 2066). MRYs selected using Isev seem to be more severe than years selected by MI; therefore, 2009 and 2066 were selected as the MRYs for this study.

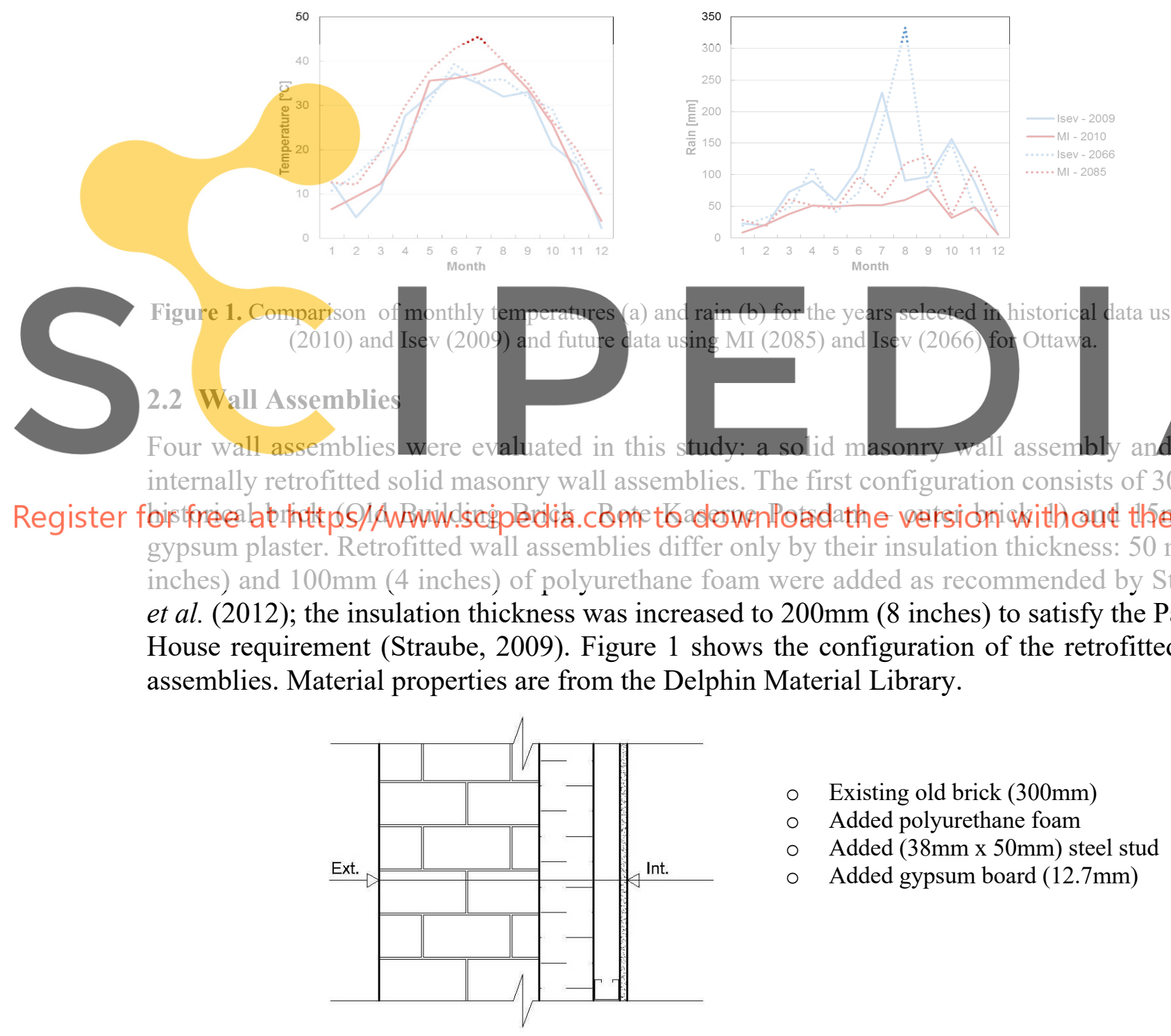

Figure 2. Solid masonry Wall retrofit solution. 


\subsection{Stochastic Model's Setup}

The stochastic models were generated according to the stochastic hygric material properties of brick. The Latin Hypercube Sampling method was applied to generate the stochastic models (Wang and Ge, 2018). The basic material parameters such as effective saturation ( $\theta_{\text {eff }}$ ), water vapor diffusion resistance factor at dry state $(\mu)$ and liquid water conductivity at effective saturation $\left(\mathrm{k}_{1}\right)$ are considered as stochastic variables. Their mean values were based on DELPHIN material properties. Whereas, the standard deviation was calculated as a function of the coefficient of variance $(\mathrm{CV})$. Values of $\mathrm{CV}$ were found for a similar type of brick in the literature (Zhao et al., 2015). Descriptive statistics of material properties of the specific old brick material are presented in Tables 2 and 3.

Table 2. Deterministic parameters of brick.

\begin{tabular}{lcc}
\hline $\begin{array}{l}\text { Material } \\
\text { property }\end{array}$ & Unit & Mean \\
\hline$\rho$ & {$\left[\mathrm{kg} / \mathrm{m}^{3}\right]$} & 1842.47 \\
\hline $\mathrm{c}$ & {$[\mathrm{J} / \mathrm{kgK}]$} & 772.224 \\
\hline $\boldsymbol{\lambda}$ & {$\left[\mathrm{W} / \mathrm{mK}^{3}\right]$} & 0.7975 \\
\hline $\boldsymbol{\theta}_{\text {por }}$ & {$\left[\mathrm{m}^{3} / \mathrm{m}^{3}\right]$} & 0.304727 \\
\hline $\boldsymbol{\theta}_{\text {cap }}$ & {$\left[\mathrm{m}^{3} / \mathrm{m}^{3}\right]$} & 0.255 \\
\hline $\mathbf{A}_{\mathrm{w}}$ & {$\left[\mathrm{kg} / \mathrm{m}^{2} \mathrm{~s}^{0.5}\right]$} & 0.0668929 \\
\hline
\end{tabular}

Table 3. Stochastic parameters of brick.

\begin{tabular}{lcccc}
\hline $\begin{array}{l}\text { Material } \\
\text { property }\end{array}$ & Unit & Mean & Std dev & $\begin{array}{c}\text { CV } \\
(\%)\end{array}$ \\
\hline$\theta_{\text {eff }}$ & {$\left[\mathrm{m}^{3} / \mathrm{m}^{3}\right]$} & 0.28399 & 0.00954 & 3.36 \\
\hline$\mu$ & {$[-]$} & 37.5558 & 9.8734 & 26.29 \\
\hline $\mathrm{kl}$ & {$[\mathrm{s}]$} & $2 \mathrm{E}-8$ & $5.248 \mathrm{E}-09$ & 26.24 \\
\hline
\end{tabular}
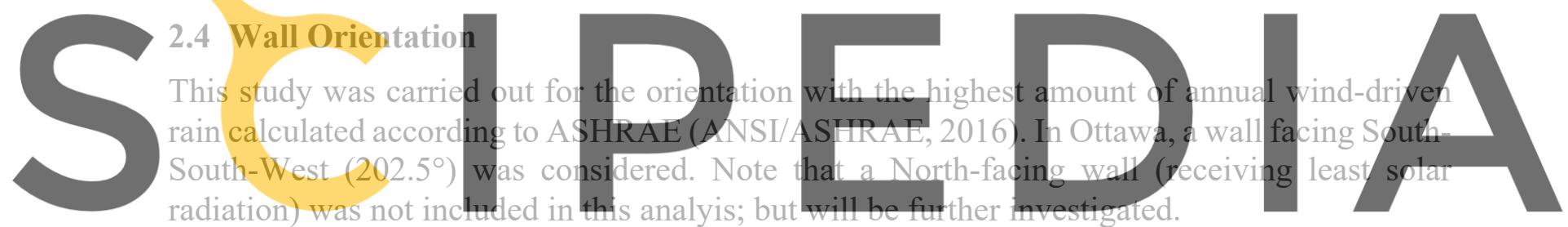

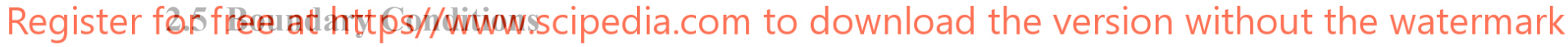

\subsubsection{Indoor boundary conditions}

The indoor relative humidity was computed using the ASHRAE 160 simple method (ANSI/ASHRAE, 2016). The indoor temperature was also calculated using the same model for heating only. As for the indoor vapour diffusion and the indoor heat conduction coefficients, they were assumed as $1.52 * 10^{-8} \mathrm{~s} / \mathrm{m}$ and $8 \mathrm{~W} / \mathrm{m}^{2} \mathrm{~K}$, respectively.

\subsubsection{Outdoor boundary conditions}

Outdoor boundary conditions include heat conduction, vapor diffusion, wind driven rain, short wave radiation and long wave radiation. To compute the longwave radiation, the boundary layer method was selected in Delphin. The required longwave emission coefficient of the building surface was set to 0.9 . And the convective heat transfer coefficient was calculated based on Equation (1):

$$
h_{c e}=4+4 . v
$$


Where, $v$ is the wind speed. The reflection coefficient of the surrounding ground (albedo) was 0.2 and the absorptance coefficient of the brick cladding surface was equal to 0.6.

\subsubsection{Wind-driven rain}

WDR is calculated using ASHRAE method (ANSI/ASHRAE, 2016) for a 3.5 storey building located in the suburban area. Assuming a medium exposure factor, the rain exposure factor $\left(\mathrm{F}_{\mathrm{E}}\right)$ and the rain deposition factor $\left(\mathrm{F}_{\mathrm{D}}\right)$ were set to 1.0 and 0.5 , respectively.

\subsection{Initial Conditions}

Initial temperature and relative humidity conditions were selected as constants and set to $21^{\circ} \mathrm{C}$ and $50 \%$, respectively.

\subsection{Performance Indicator for Assessing Wall Performance}

One of the most important damage mechanisms in porous materials is caused by the action of freezing and thawing inside materials (K.R. Lisø et al., 2007 G.; Wardeh and B. Perrin, 2008). The onset of freeze-thaw damage in porous materials requires that the value of moisture saturation is exceeded simultaneously with the occurrence of freezing temperatures. According to Straube et al. (2006), the critical degree of moisture saturation (Scrit) of masonry can vary considerably among different types of historical brick. For instance, following an experimental study using frost dilatometry, the Scrit of three brick stones foundin Canada was found between
0.25 and 0.87 (Straube et al., 2010). In this paper, values of (Scrit) equal to $0.25,0.35,0.5$ and
0.8 were considered. Also, freezing is considered to occur at ternperatures below $-5^{\circ} \mathrm{C}$ within
the material (Straube and Schunacher, 2006). The risk of freeze-thaw damage is computed
using the critical number of freeze-thaw cycles (FTC). One cycle is counted when temperature
decreases below the freezing temperature and moisture content exceeds its critical level.

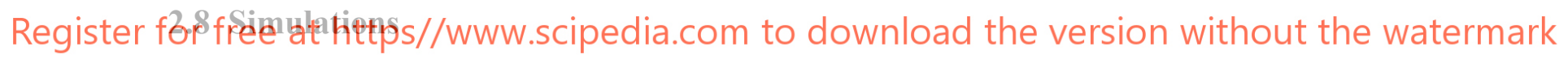

Simulations were performed for the base and retrofitted walls under historical and future loads, using hygrothermal simulation program Delphin 5, v5.9.4. No air and moisture leakage source were assumed. Simulations were executed over a period of five years using the reference year for each time-period; meaning that each selected year is repeated 5 times. However, only the results of the $5^{\text {th }}$ year are evaluated.

A fine variable discretization, with a minimum element width of $0.5 \mathrm{~mm}$ and a stretch factor of 125 was used to set up the meshing of the materials. The point of investigation was placed at a depth of $5 \mathrm{~mm}$ of the brick surface.

\section{Results and Discussion}

Figure 3 shows the impact of interior insulation thickness on the estimated number of freezethaw cycles (FTC) of an old brick masonry wall located in Ottawa and modelled for historical and future climatic loads. The brick was tested for different critical degree of saturation: 0.25, $0.35,0.5$ and 0.8. However, Figure 3 shows stochastic results for Scrit equals to 0.25 and 0.35 only. For higher saturation degrees, i.e., brick having higher resistance properties, the insulation thickness did not have any influence on the durability of the masonry wall. Estimated FTCs 
indicated zero; therefore no potential risk to freeze-thaw damage to occur. Therefore, only results for a brick with Scrit equal 0.25 and 0.35 will be discussed.
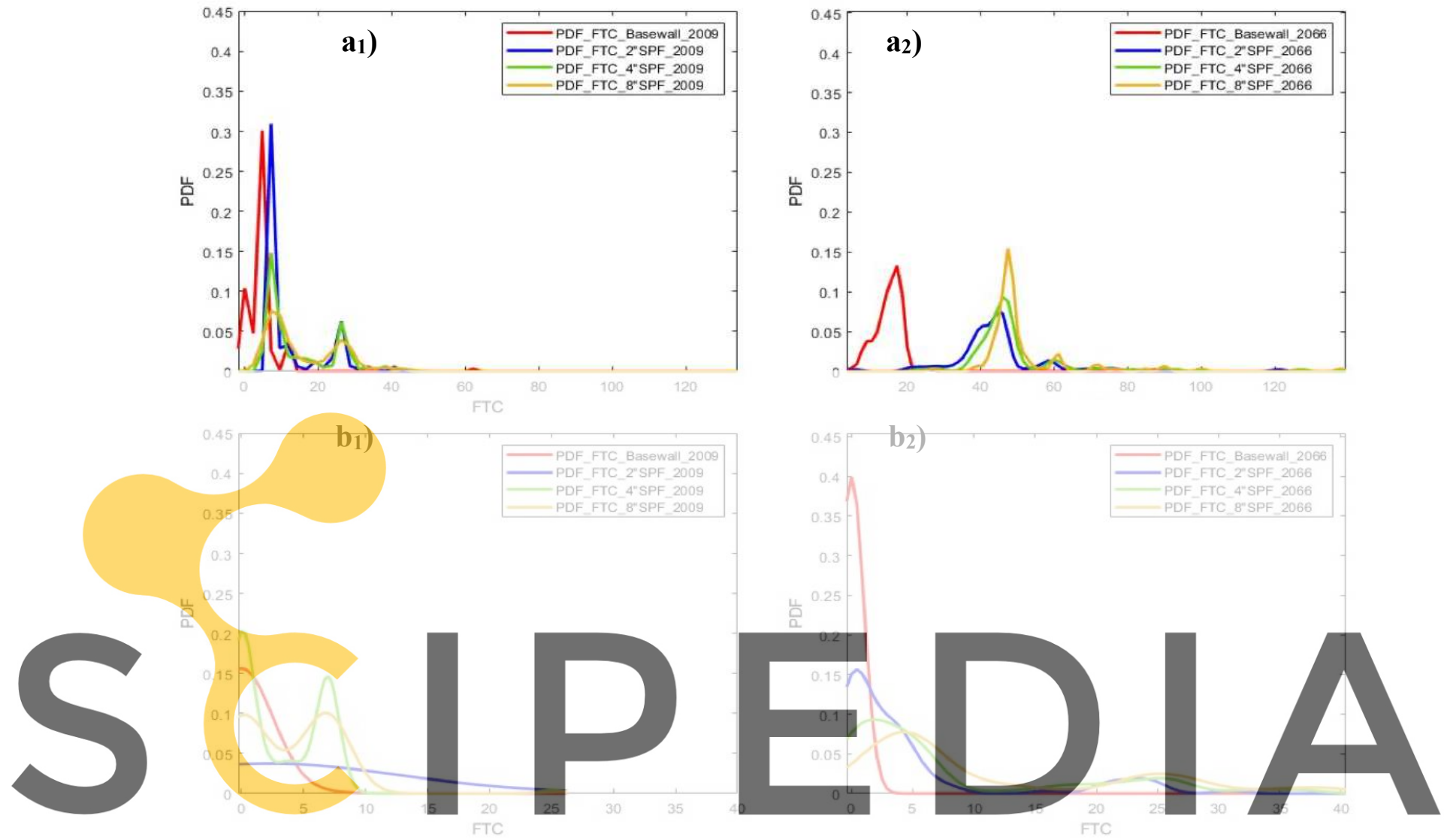

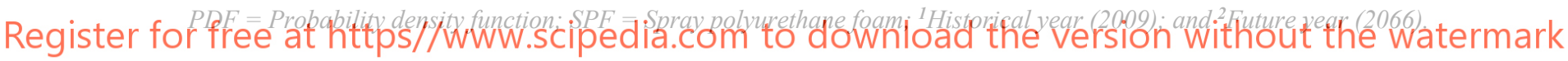 \\ Figure 3. Stochastic results - the impact of insulation thickness on the estimated number of freeze-thaw cycles \\ (FTC) for brick masonry having a critical degree of saturation of a) Scrit $=0.25$; and b) Scrit $=0.35$.}

In general, after interior insulation was added, the number of FTCs increased, indicating a higher potential of freeze-thaw to occur. For instance, FTC values varied between 0 and 12 for a base wall with Scrit $=0.25$. These values increased to range between 5 and 30 FTCs when 2" of insulation was added. When adding a larger insulation thickness of 4" and 8", the number of FTCs reached a range of [5 - 42] and [5 - 50], respectively (Figure 3-a a $_{1}$. The probability distribution of FTCs for the same type of brick under future climate denoted a larger difference between the base wall and the retrofitted options. While values of FTC varied between 0 and 22 for a base wall, added insulation has caused the FTC to range between 0 and 100, with a higher probability around 50 cycles (Figure $3-a_{2}$ ). When the Scrit is 0.35 (Figure $3-b_{1}$ and Figure $3-b_{2}$ ), adding insulation still has increased the number of FTC; however, with less discrepancies.

Table 4 represents the deterministic results of the predicted number of freeze-thaw cycles. Comparing results obtained by the deterministic and the stochastic methods, they seem in good agreement. Values of FTCs calculated using the deterministic approach corresponds in most of the cases to the FTC number having the highest density within the stochastic results range. 
Table 4. Estimated number of FTC results for the deterministic method.

\begin{tabular}{cccccccccccccc}
\hline & \multicolumn{4}{c}{ Basewall } & \multicolumn{3}{c}{ 2" added insulation } & \multicolumn{3}{c}{ 4" added insulation } & \multicolumn{2}{c}{ 8" added insulation } \\
\hline Scrit & 0.25 & 0.35 & $0.5-0.8$ & 0.25 & 0.35 & $0.5-0.8$ & 0.25 & 0.35 & $0.5-0.8$ & 0.25 & 0.35 & $0.5-0.8$ \\
\hline $\mathbf{2 0 0 9}$ & 5 & 0 & 0 & 24 & 2 & 0 & 29 & 6 & 0 & 32 & 7 & 0 \\
\hline $\mathbf{2 0 6 6}$ & 5 & 0 & 0 & 49 & 2 & 0 & 52 & 9 & 0 & 56 & 21 & 0 \\
\hline
\end{tabular}

Figure 4 illustrates the impact of climate change on the potential risk to freeze-thaw damage. Stochastic results clearly show that FTC increased in number and spread under future conditions. Deterministic results in Table 4 demonstrated the same as well.

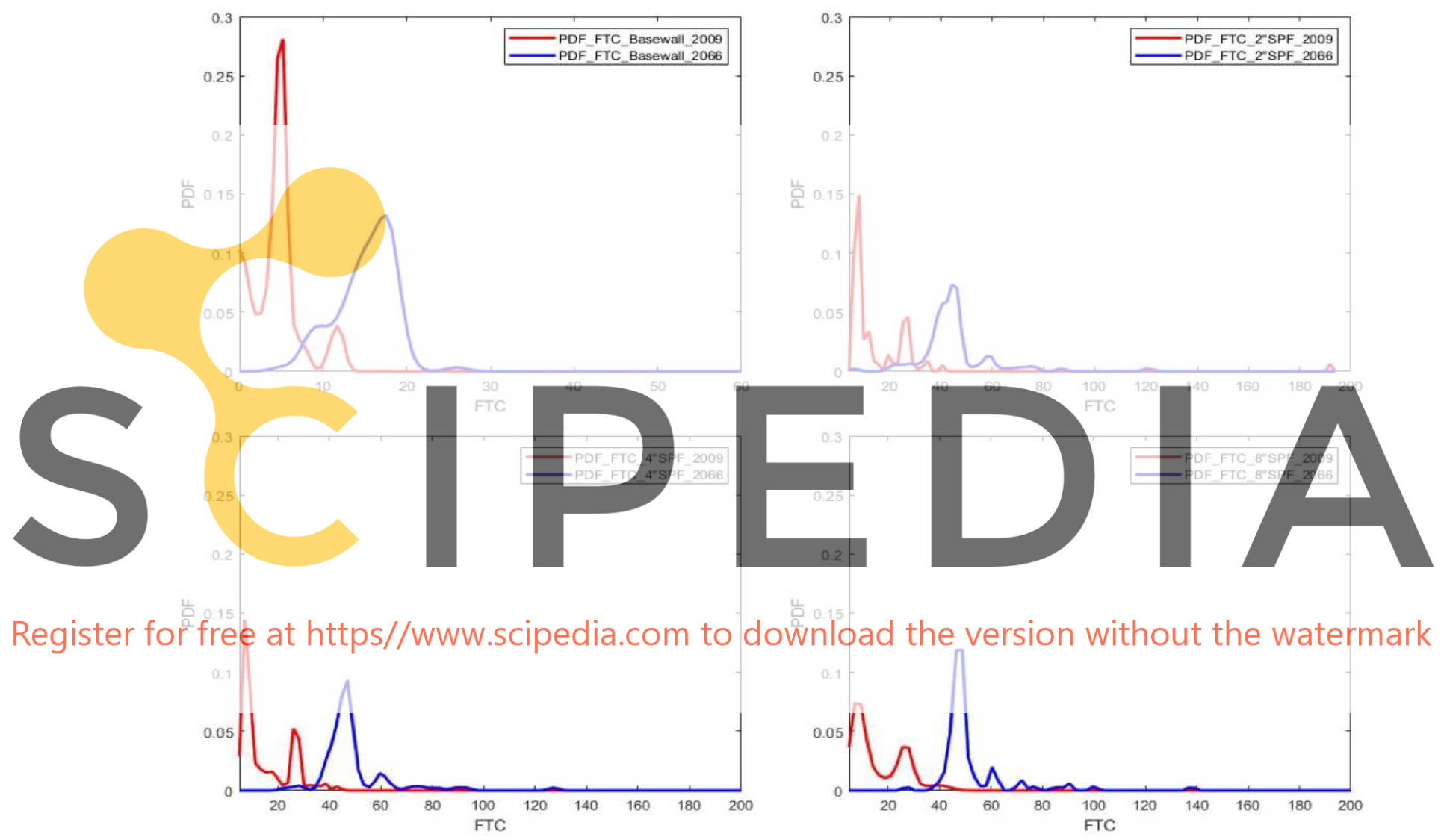

Figure 4. Stochastic results - the climate change effect on the estimated number of FTC for brick masonry having a Scrit of 0.25 .

\section{Conclusions}

The durability performance of a masonary basewall and three retrofit alternatives of the same wall, having three different insulation thicknesses were evaluated using both a deterministic and a stochastic method. This study took into account the uncertainties in brick masonry properties under historical and future climate conditions. The brick was tested for different critical degree of saturation: $0.25,0.35,0.5$ and 0.8 . The insulation thickness did not have any influence on the durability of the masonry brick with better frost resistance, i.e. higher critical degree of saturation of 0.5 and 0.8 . However, for a Scrit of 0.25 and 0.35 , the number of FTCs 
increased, indicating a higher potential of freeze-thaw to occur. Results obtained by the deterministic and the stochastic methods were in good agreement, as values of FTCs calculated using the deterministic approach correspond to the number of FTC having the highest probability within the stochastic results range. In addition, both methods showed an increase in FTCs' number and spread under future conditions; thus, a higher risk to frost damage. To provide a safe insulation type and thickness range for the retrofit of masonry walls and to account for the uncertainty of future climate, a study will be carried out later.

\section{ORCID}

Sahar Sahyoun: https://orcid.org/0000-0001-5131-6134

Lin Wang: https://orcid.org/0000-0002-6529-1123

Hua Ge: http://orcid.org/0000-0003-1368-4301

Maurice Defo: http://orcid.org/0000-0001-9212-6599

Michael Lacasse: https://orcid.org/0000-0001-7640-3701

References

ANSI/ASHRAE. (2016). Criteria for Moisture Control Design Analysis in Buildings. Atlanta.

ASHRAE. (2010). Environmental weather loads for hygro- thermal analysis and design of buildings. RP-1325, American Society of Heating, Refrigerating and Air-Conditioning Engineers, Inc. Atlanta.

Cornick, S., Djebbar, R. and Dalgliesh A.W. (2003). Selecting moisture reference years using a Moisture Index approach. Building and Environment, 38(12), 1367-1379.

Environment and Climate Change Canada. (2018). Memorandum of Understanding between National Research Council and Environment and Cimate Change Canda.... Government of Canada: Ottawa, ON. Canada.

Gaur, A., Lacasse, M. and A Simulations Under Proje

IPCC. (2001). Climate Change Change Third Assessmen

Lisø, K. R., Kvande, T., Hy. porous, mineral building materiais.
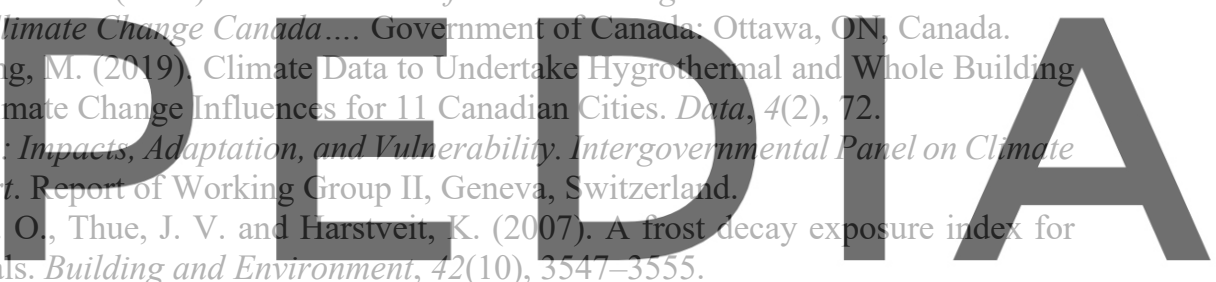

Straube, J. and Schumacher, C. (2006). Assessing the durability impacts of energy efficient enclosure upgrades

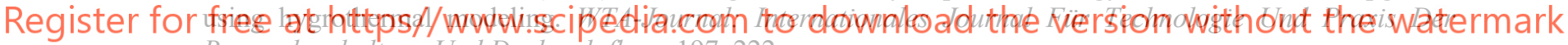
Bauwerkserhaltung Und Denkmalpflege, 197-222.

Straube, J. (2009). BSI-025: The Passive House (Passivhaus) Standard-A comparison to other cold climate lowenergy houses. Building Science Corporation, Somerville, Massachusetts, USA.

Straube, J., Schumacher, C. and Mensinga, P. (2010). Assessing the freeze-thaw resistance of clay brick for interior insulation retrofit projects. Proceedings of the Performances of Envelopes of Whole Buildings XI, 1-8.

Straube, J. F., Ueno, K. and Schumacher, C. J. (2012). Measure guideline: internal insulation of masonry walls (No. DOE/GO-102012-3523). National Renewable Energy Lab. (NREL), Golden, CO (United States).

Wang, L. and Ge, H. (2018). Stochastic modelling of hygrothermal performance of highly insulated wood framed walls. Building and Environment, 146, 12-28.

Wardeh, G. and Perrin, B. (2008). Freezing-thawing phenomena in fired clay materials and consequences on their durability. Construction and Building Materials, 22(5), 820-828.

Zhao, J., Plagge, R., Ramos, N. M., Simões, M. L. and Grunewald, J. (2015). Concept for development of stochastic databases for building performance simulation-A material database pilot project. Building and environment, 84, 189-203. 